\title{
Wildfire Smoke Exposure: Covid19 Comorbidity?
}

\author{
Ira Leifer ${ }^{1, *}$, Michael T. Kleinman ${ }^{2}$, Donald Blake ${ }^{3}$, David Tratt ${ }^{4}(D)$ and Charlotte Marston ${ }^{1}$ \\ 1 Bubbleology Research International, Solvang, CA 93463, USA; charlotte.marston@bubbleology.com \\ 2 Department of Medicine, University of California, Irvine, CA 92697, USA; mtkleinman@uci.edu \\ 3 Department of Chemistry, University of California, Irvine, CA 92697, USA; drblake@uci.edu \\ 4 The Aerospace Corporation, El Segundo, CA 90245, USA; david.m.tratt@aero.org \\ * Correspondence: ira.leifer@bubbleology.com; Tel.: +1-805-683-3333
}

Academic Editor: Paul Zarogoulidis

Received: 17 January 2021; Accepted: 5 February 2021; Published: 12 February 2021

\begin{abstract}
Air pollution, particularly fine and ultrafine particulate matter aerosols, underlies a wide range of communicable and non-communicable disease affecting many systems including the cardiopulmonary and immune systems, and arises primarily from transportation and industry. A number of air pollution driven diseases also are Covid19 comorbidities. Thus, a number of studies on air pollution exposure, particularly particulate matter, strongly indicate air pollution is an important underlying factor in Covid19 transmission, severity, and mortality. This suggests that air pollution from natural sources, particularly wildfires, could play a role in the Covid19 pandemic. We tested this hypothesis on three wildfire smoke events in Orange County, CA, each of which was followed by Covid19 case increases after an approximately one-week lag. This lag was consistent with combined incubation time and testing/reporting times. Moreover, the three events suggest a dose dependency. The wildfire comorbidity hypothesis implies that at-risk-populations should reduce smoke exposure from wildfires, as well as indoors from biomass burning for heating, cooking, and aesthetic purposes.
\end{abstract}

Keywords: Covid19; air pollution; cardiopulmonary disease; wildfire; particulate matter; infectious disease

\section{Introduction}

Air pollution long has been recognized as contributing to non-communicable disease, affecting a wide range of systems (respiratory, cardiovascular, neurological, renal, hepatic, endocrine), diabetes and cancer [1] and communicable diseases [2]. Air pollution is a primary cause of morbidity with recent global annual mortality estimated at 8.9 million for fine particulate matter $\left(\mathrm{PM}_{2.5},<2.5 \mu \mathrm{m}\right)$ exposure [3]. Anthropogenic air pollution in the developed world arises primarily from transportation and industry, whereas in the developing world, woodfire cooking and heating smoke also are important air pollution sources [1]. Although air pollution health research has focused primarily on anthropogenic pollution, wildfire smoke increasingly is recognized as a driver of respiratory and cardiovascular diseases [4].

Inhaled PM affects immune system function and thus can increase susceptibility to infectious respiratory diseases $[2,5,6]$. For example, children exposed acutely and/or chronically to elevated PM levels experienced increased and longer hospitalizations for pneumonia [2]. In a study of 500,000 adults, exposure to elevated $\mathrm{PM}_{2.5}$ was associated with increased adult pneumonia and influenza infection rates after a 5-to-7-day lag [7].

Size matters, with ultrafine aerosols $\left(\mathrm{PM}_{0.1},<0.1 \mu \mathrm{m}\right)$ playing a potentially significant role-smaller aerosols penetrate deeper into the lungs where clearance is slower. Pulmonary clearance first occurs rapidly ( $\sim 3 \mathrm{~h}$ half life) and then slowly ( $\sim 3$ months half-life) [8], giving rise to persistent health impacts. Additionally, $\mathrm{PM}_{0.1}$ crosses any biological barrier and travels freely in the blood, driving inflammation 
in many organs including the brain where it induces chronic neuroinflammation that exacerbates neurodegenerative diseases [9].

Air pollution-associated diseases share characteristics with Covid19 comorbidities, suggesting a commonality between pollution-exposure induced pathology and that of Covid19 as described in recent reviews $[6,10,11]$ amongst others). Both Covid19 and air pollution induce inflammation, oxidative stress, and cell damage throughout the respiratory tract [10]. The relationship is highly significant with Pozzer et al. [11] estimating that air pollution exposure could explain 15\% (7-33\%) of Covid19 mortality globally and 17\% (6-39\%) in North America.

Air pollution affects Covid19 susceptibility by decreasing adaptive immune system recognition and thus response to viral infections and also by impairing innate immunity functions such as macrophage phagocytosis, clearance of viral particles, and reduced respiratory burst activity to kill viruses. Air pollution also dilutes immune response from viruses to particles and damaged lung tissue $[2,10]$. Furthermore, $\mathrm{PM}_{2.5}$ causes respiratory tract inflammation, immune dysregulation, and over-expression of Angiotensin-Converting Enzyme-2 (ACE-2), which is linked to the pathway by which Covid19 enters and infects cells. Thus, air pollution causes an inappropriate immune response that significantly increases infection risks for Covid19 [12] and other communicable diseases such as influenza [5].

Air pollution increases Covid19 severity [12]. Severe symptoms of Covid19 are associated with high levels of inflammatory markers, a cytokine storm, and inflammatory lung damage, which also are associated with air pollution exposure [6]. Air pollution contributes indirectly to disease severity though the exacerbation and onset of disease such as chronic obstructive pulmonary disease (COPD), asthma, cardiopulmonary disease, hypertension, and diabetes, which also are Covid19 comorbidities [10]. Both Covid19 and air pollution contribute to neurodegenerative diseases and their manifestations. For example, chronic exposure to elevated PM downregulates ACE-2 and causes oxidative stress, both of which increase Covid19 entry to cells [12] including neurons leading to neuroinflammation [9].

Wildfire smoke pollution is of growing importance due to climate change with similarities in composition and health effects between anthropogenic and wildfire air pollution, yet, wildfire smoke health effects have received inadequate attention [4]. One such effect is the potential for increased Covid19 transmission due to acute wildfire PM exposure [13] with possible contributions from other wildfire pollutants, such as ozone, which is recognized as a cause of urban air pollution diseases, including cardiopulmonary disease [3]. Wildfires also include other trace gases like carbon monoxide, which was related to cumulative Covid19 cases in Northern California [14]. Notably, wildfires during a pandemic create a cascading disaster with disruption to directly-affected communities challenging mitigation practices such as social distancing in evacuation shelters [15], while local disaster responses (including healthcare) are multiply stressed, i.e., synergies that likely increase Covid19 cases and negative outcomes.

The exceptional late summer California 2020 wildfires and the Covid19 pandemic in California provided an opportunity to test the hypothesis that following wildfire smoke events in southern California, reported incidences of Covid19 infections would be elevated relative to expected incidence rates. These smoke events were not from local wildfires.

\section{Experimental Section}

Air quality time series data were downloaded from https://monitoring.cleanairactionplan.org/ on 3 December 2020. Gaps in air quality data (for regular calibration) were filled by linear interpolation using custom routines written in Matlab (Mathworks, Natick, MA, USA). Data then were smoothed by a running mean-filter $(6 \mathrm{~h})$ using the smooth.m function.

Coronavirus case data for Orange County were downloaded from https://data-ocpw.opendata. arcgis.com/ on 2 December 2020. Data were 7-day running-mean-filter smoothed to remove artifacts related to low weekend reporting. Data for the exploratory study were segregated into baseline and outbreak data periods. Fits were conducted on the baseline data using the fit.m tool in Matlab 
(Mathworks, Natick, MA, USA). For the period 6 September 2020 to 29 October 2020 a linear polynomial was fit to the data. For the period 26 October 2020 to 17 November 2020, a Gaussian function was fit to the data. A Gaussian function better represented this growth period than other functional forms including an exponential. This exponential also reasonably well-represented the July case peak for Orange County.

\section{Results}

An exploratory test of this hypothesis was performed for three significant fall 2020 wildfire-related $\mathrm{PM}_{2.5}$ events in Orange County, California during a period when the Southern California climate is mild (activities remained in summer outdoor patterns) and there were no stay-in-place orders in effect. Each wildfire-related $\mathrm{PM}_{2.5}$ event lasted $\sim 1$ week and caused highly-elevated exposures (Figure 1A). These wildfire smoke events were followed by Covid19 case increases above the existing trend after an approximately 1-week lag. This lag is similar to lags for other air pollution respiratory diseases such as influenza and pneumonia after air pollution events (Croft et al., 2019). Additionally, one week is consistent with the time for Covid19 incubation plus a few days for test reporting. Elevated cases lasted for a further week (Figure 1B,C), approximately the same duration as the wildfire smoke events' durations. Cases for the third event occurred during the start of the rapid growth in California Covid19 cases in fall 2020. As such, its magnitude may be more uncertain than the previous events.

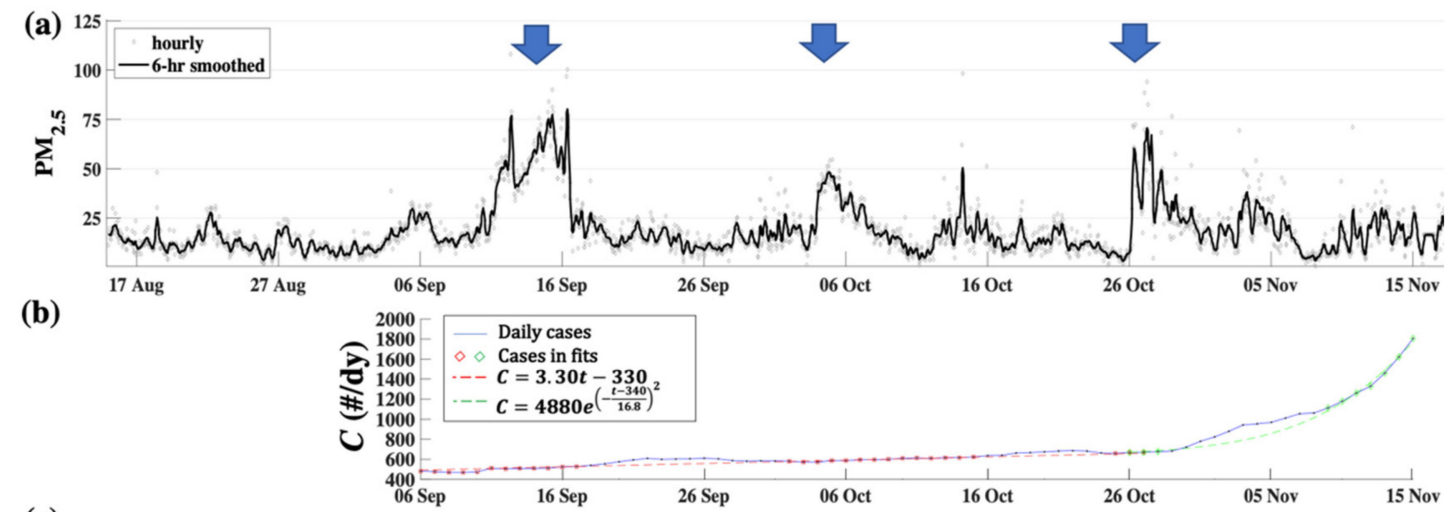

(c)

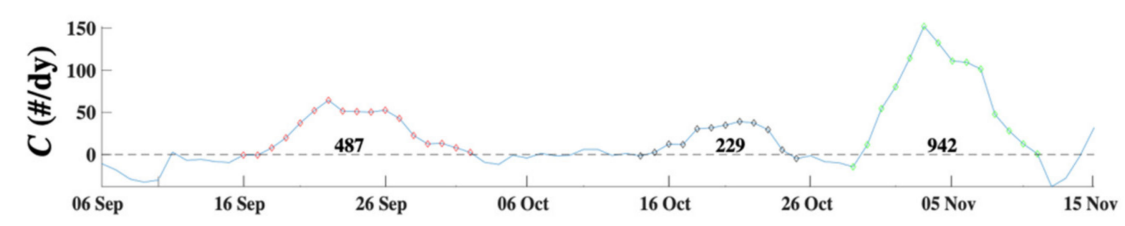

Figure 1. (a) Hourly and 6-h smoothed graphs of fine particulate matter, $\mathrm{PM}_{2.5}$, for San Pedro (Los Angeles Basin), CA, arrows show wildfire smoke events. (b) Seven-day rolling-averaged Covid19 cases for Orange County, $C$, versus day, $t$, (referenced to 1 January 2020), $C$ used in fits, and linear and Gaussian fits. See data key. (c) Residual with the total number of excess cases in each peak shown on figure.

There is a suggestion of dose dependency with larger integrated $\mathrm{PM}_{2.5}$ events relating to large outbreaks. This would imply higher case numbers for populations more proximate to the wildfires, which would have received higher "doses".

\section{Discussion}

These findings suggest that wildfire smoke exposure could be a Covid19 potentiator whose impacts superimpose on the health impacts from normal urban pollution. Wildfire $\mathrm{PM}_{2.5}$ are comparable to normal urban pollution levels over wide regions (i.e., Figure 1A) and can be more oxidative and toxic [4]. In areas more proximate to wildfires, wildfire smoke pollution levels can far exceed 
ambient levels including those shown in Figure 1. In a study of San Francisco, Covid19 cases and air pollution showed a significant positive correlation between $\mathrm{PM}_{2.5}$ and daily Covid19 cases and a stronger positive correlation with cumulative cases and mortality [14]. Other factors such as climate or Non-Pharmaceutical Interventions (NPI) were not included in their analysis. Meo et al. [16] looked at air pollution including carbon monoxide in ten northern California counties and found positive temporal correlations with daily Covid19 cases and outcomes. Notably, wildfires also severely impacted some of these counties. Wildfire disaster response disrupts pandemic response, e.g., mass evacuations and refugee concentrations in shelters makes NPIs challenging [15] and can increase transmission.

This study focused on wildfire smoke exposure in Orange County, which was distant from the wildfires (i.e., no disaster response, evacuations, etc.) and whose mild climate meant activities had not shifted indoors, unlike in northern California. Nevertheless, factors including NPI policies such as those related to indoor/outdoor dining and mask wearing (of uncertain enforcement and compliance) only affects the overall case trend, not the short-lived periods of excess cases.

Wildfire pollution health impacts are likely the greatest amongst proximate communities and for exposed minority and impoverished "essential" worker populations whose employment requires significant outdoor time, largely without appropriate protection (N95 mask). Of particular concern is wildfire firefighter smoke exposure, which could lead to higher Covid19 risk and who currently only use cloth masks for protection [17]. On a local level, by analogy, biomass or wood burning in homes for aesthetics, heating, or cooking may be increasing risks for homeowners and their neighbors.

A mechanistic pathway for wildfire smoke-associated respiratory disease is oxidative stress. Studies have identified inflammatory markers in exposed populations and reduced bronchial macrophage counts and enhanced cytokine levels for animals exposed to California wildfire smoke [18]. Exposure to wildfire smoke also results in similar increased expression of inflammatory markers [19], in common with Covid19 and urban air pollution. Wildfire smoke health pathways are proposed to be similar to pathways for anthropogenic pollution or wood cooking and heating smoke [20]. Currently, there is a paucity of detailed mechanistic and long-term studies despite research showing significant health impacts from short-term wildfire smoke exposure [4,20]. Nevertheless, long-term health impacts are expected by analogy with air pollution health impacts that persist on lung-clearance timescales, i.e., months or longer.

This exploratory study is based on a limited dataset. A more comprehensive study could quantify the dose dependency and also incorporate other factors such as ethnicity and income levels. Additionally, wildfire smoke contains other pollutants that could be explored in a larger dataset.

We propose that given the likely persistence of Covid19 in 2021, there will be wildfire smoke impacts on Covid19 in 2021 that should be considered by policy makers and researchers. Considering wildfire as a "comorbidity factor" suggests significant and urgent policy recommendations, particularly as a potential contributor to the spread of Covid19 and other infectious diseases. At-risk-populations, e.g., medical personnel, elderly, firefighters, etc., should be encouraged to use N95 masks, if available, rather than surgical masks when outdoors during wildfire smoke events. Indoor high efficiency particulate air (HEPA) filtration could help reduce exposures in indoor public settings where transmission is likely, e.g., airports, mass transit, etc. Populations with Covid19 comorbidities that are impacted by $\mathrm{PM}_{2.5}$, such as pre-existing heart and lung diseases, should consider minimizing outdoor exposure during wildfire smoke events. These populations also should consider home precautions including room/house HEPA filtration, avoiding woodfire heating and cooking, etc.

Author Contributions: I.L. and M.T.K. developed the study approach. I.L. and C.M. prepared the first draft including the literature search. I.L. conducted data analysis and prepared figures. D.T., D.B. contributed to the editing and writing. All authors contributed to the writing and editing of the manuscript. All authors have read and agreed to the published version of the manuscript.

Funding: This research received no external funding.

Institutional Review Board Statement: Not applicable.

Informed Consent Statement: Not applicable. 
Data Availability Statement: Not applicable.

Acknowledgments: We thank the Port of Los Angeles for providing the air quality data used in this study.

Conflicts of Interest: The authors declare no conflict of interest.

\section{References}

1. Schraufnagel, D.E.; Balmes, J.R.; Cowl, C.T.; De Matteis, S.; Jung, S.-H.; Mortimer, K.; Perez-Padilla, R.; Rice, M.B.; Riojas-Rodriguez, H.; Sood, A.; et al. Air pollution and Noncommunicable Diseases: A Review by the Forum of International Respiratory Societies' Environmental Committee, Part 2: Air Pollution and Organ Systems. Chest 2019, 155, 417-426. [CrossRef] [PubMed]

2. Domingo, J.L.; Rovira, J. Effects of Air Pollutants on the Transmission and Severity of Respiratory Viral Infections. Environ. Res. 2020, 187, 109650. [CrossRef] [PubMed]

3. Burnett, R.; Chen, H.; Szyszkowicz, M.; Fann, N.; Hubbell, B.; Pope, C.A.; Apte, J.S.; Brauer, M.; Cohen, A.; Weichenthal, S.; et al. Global Estimates of Mortality Associated with Long-Term Exposure to Outdoor Fine Particulate Matter. Proc. Natl. Acad. Sci. USA 2018, 115, 9592-9597. [CrossRef] [PubMed]

4. Xu, R.; Yu, P.; Abramson, M.J.; Johnston, F.H.; Samet, J.M.; Bell, M.L.; Haines, A.; Ebi, K.L.; Li, S.; Guo, Y. Wildfires, Global Climate Change, and Human Health. N. Engl. J. Med. 2020, 383, 2173-2181. [CrossRef] [PubMed]

5. Glencross, D.A.; Ho, T.-R.; Camiña, N.; Hawrylowicz, C.M.; Pfeffer, P.E. Air Pollution and Its Effects ON The Immune System. Free Radic. Biol. Med. 2020, 151, 56-68. [CrossRef] [PubMed]

6. Woodby, B.; Arnold, M.M.; Valacchi, G. SARS-CoV-2 Infection, COVID-19 Pathogenesis, and Exposure to Air Pollution: What Is the Connection? Ann. N. Y. Acad. Sci. 2020. [CrossRef] [PubMed]

7. Croft, D.P.; Zhang, W.; Lin, S.; Thurston, S.W.; Hopke, P.K.; Masiol, M.; Squizzato, S.; van Wijngaarden, E.; Utell, M.J.; Rich, D.Q. The Association between Respiratory Infection and Air Pollution in the Setting of Air Quality Policy and Economic Change. Ann. Am. Thorac. Soc. 2019, 16, 321-330. [CrossRef] [PubMed]

8. Moller, W.; Haussinger, K.; Winkler-Heil, R.; Stahlhofen, W.; Meyer, T.; Hofmann, W.; Heyder, J. Mucociliary and Long-Term Particle Clearance in the Airways of Healthy Nonsmoker Subjects. J. Appl. Physiol. 2004, 97, 2200-2206. [CrossRef] [PubMed]

9. Calderón-Garcidueñas, L.; Torres-Jardón, R.; Franco-Lira, M.; Kulesza, R.; González-Maciel, A.; Reynoso-Robles, R.; Brito-Aguilar, R.; García-Arreola, B.; Revueltas-Ficachi, P.; Barrera-Velázquez, J.A.; et al. Environmental Nanoparticles, SARS-CoV-2 Brain Involvement, and Potential Acceleration of Alzheimer's and Parkinson's Diseases in Young Urbanites Exposed to Air Pollution. J. Alzheimer Dis. 2020, 78, 479-503. [CrossRef] [PubMed]

10. Comunian, S.; Dongo, D.; Milani, C.; Palestini, P. Air Pollution and Covid-19: The Role of Particulate Matter in the Spread and Increase of Covid-19's Morbidity and Mortality. Int. J. Environ. Res. Public Health 2020, 17, 4487. [CrossRef] [PubMed]

11. Pozzer, A.; Dominici, F.; Haines, A.; Witt, C.; Münzel, T.; Lelieveld, J. Regional and Global Contributions of Air Pollution to Risk of Death from COVID-19. Cardiovasc. Res. 2020, 116, 2247-2253. [CrossRef] [PubMed]

12. Borro, M.; Di Girolamo, P.; Gentile, G.; De Luca, O.; Preissner, R.; Marcolongo, A.; Ferracuti, S.; Simmaco, M. Evidence-Based Considerations Exploring Relations between SARS-CoV-2 Pandemic and Air Pollution: Involvement of PM2.5-Mediated Up-Regulation of the Viral Receptor ACE-2. Int. J. Environ. Res. Public Health 2020, 17, 5573. [CrossRef] [PubMed]

13. Henderson, S.B. The COVID-19 Pandemic and Wildfire Smoke: Potentially Concomitant Disasters. Am. J. Public Health 2020, 110, 1140-1142. [CrossRef] [PubMed]

14. Meo, S.A.; Abukhalaf, A.A.; Alomar, A.A.; Alessa, O.M. Wildfire and COVID-19 Pandemic: Effect of Environmental Pollution PM-2.5 and Carbon Monoxide on the Dynamics of Daily Cases and Deaths due to SARS-COV-2 Infection in San-Francisco USA. Eur. Rev. Med. Pharmacol. Sci. 2020, 24, 10286-10292. [CrossRef] [PubMed]

15. Salas, R.N.; Shultz, J.M.; Solomon, C.G. The Climate Crisis and Covid-19-A Major Threat to the Pandemic Response. N. Engl. J. Med. 2020, 383, e70. [CrossRef] [PubMed]

16. Meo, S.A.; Abukhalaf, A.A.; Alomar, A.A.; Alessa, O.M.; Sami, W.; Klonoff, D.C. Effect of Environmental Pollutants Pm-2.5, Carbon Monoxide, and Ozone on the Incidence and Mortality of SARS-COV-2 Infection in Ten Wildfire Affected Counties in California. Sci. Total Environ. 2021, 757, 143948. [CrossRef] [PubMed] 
17. Navarro, K.M.; Clark, K.A.; Hardt, D.J.; Reid, C.E.; Lahm, P.W.; Domitrovich, J.W.; Butler, C.R.; Balmes, J.R. Wildland Firefighter Exposure to Smoke and COVID-19: A New Risk on the Fire Line. Sci. Total Environ. 2021, 760, 144296. [CrossRef] [PubMed]

18. Wegesser, T.C.; Franzi, L.M.; Mitloehner, F.M.; Eiguren-Fernandez, A.; Last, J.A. Lung Antioxidant and Cytokine Responses to Coarse and Fine Particulate Matter from the Great California Wildfires of 2008. Inhal. Toxicol. 2010, 22, 561-570. [CrossRef] [PubMed]

19. Black, C.; Tesfaigzi, Y.; Bassein, J.A.; Miller, L.A. Wildfire Smoke Exposure and Human Health: Significant Gaps in Research for a Growing Public Health Issue. Environ. Toxicol. Pharmacol. 2017, 55, 186-195. [CrossRef] [PubMed]

20. Schwartz, C.; Bølling, A.K.; Carlsten, C. Controlled Human Exposures to Wood Smoke: A Synthesis of the Evidence. Part. Fibre Toxicol. 2020, 17, 49. [CrossRef] [PubMed]

Publisher's Note: MDPI stays neutral with regard to jurisdictional claims in published maps and institutional affiliations.

(C) 2021 by the authors. Licensee MDPI, Basel, Switzerland. This article is an open access article distributed under the terms and conditions of the Creative Commons Attribution (CC BY) license (http://creativecommons.org/licenses/by/4.0/). 